\title{
Complex reprocessing of industrial alkaline waste of alumina production (red mud) for solving raw materials and environmental problems
}

\author{
Alexander Boyarintsev ${ }^{1, *}$, Htet Ye Aung ${ }^{1}$, Sergey Stepanov ${ }^{1}$, and Andrei Shoustikov ${ }^{1}$ \\ ${ }^{1}$ Mendeleev University of Chemical Technology, 9, Miusskaya square, 125047, Moscow, Russia
}

\begin{abstract}
Red mud are industrial large-scale toxic wastes of bauxite ore processing according to the Bayer method. They contain macrocomponents such as iron, aluminum, calcium, silicon, as well as a number of the most valuable and critical metals (microcomponents): scandium, gallium, germanium and rare earth elements (REEs), which are used in modern high-tech industry. Due to the relatively high content of scandium and REEs, red mud can be considered as a promising secondary source. Significant amounts of accumulated red mud and new flows of this waste entering the slime storage facilities need to be processed to obtaine the required valuable products. Development of complex reprocessing approach play an important role in addressing the problem of the elimination of red mud as toxic waste. Within the framework of this subject, the report considers the concept of complex reprocessing of Bogoslovsky Aluminum Plant (Russia) red mud, which includes the extraction of aluminum, scandium, REEs, zirconium and the production of iron-containing concentrate for ferrous metallurgy. The use of lowaggressive carbonate media and carbonation method using carbon dioxide gas characterizes this approach as more environmentally and technologically safe. The development of effective technology for utilization of red mud will not only provide a source of critical raw materials, but also solve the global environmental problem.
\end{abstract}

\section{Introduction}

Red mud (RM) are toxic industrial wastes of large-scale hydrochemical reprocessing of bauxite ore according to the Bayer method. Huge accumulated volumes of RM can be considered as reserves of promising multi-component secondary raw materials for the production of iron, aluminum, scandium, rare earth elements (REEs), titanium, zirconium, gallium, indium and other valuable metals. At the moment, the technology of RM processing cannot be limited only to the extraction of the most expensive components, such as scandium and REEs. To solve the problem of RM, a complex technological approach is needed with the transformation of all components into useful products used in

\footnotetext{
*Corresponding author: boyarin_sanya@mail.ru
} 
various types of industry, mainly in metallurgy or in the production of building materials [1]. In addition, complex reprocessing of RM can significantly reduce the generation of secondary waste and move to the gradual elimination of extensive slime ponds and storage facilities that occupy large land areas. Apparently, the economically justified use of RM is possible only if all the most valuable components, including iron and aluminum, are simultaneously recovered from them.

As of today, several strategies have been offered both for partial and complex reprocessing of RM with the usage of pyrometallurgical or hydrometallurgical processes, or combination thereof [2-4]. Methods for complex processing of RM involve the extraction of scandium as the most expensive and valuable component, as well as the extraction of other valuable components, and necessary inclusion in the recovery process the entire mineral base of RM.

Significant number of studies are devoted to the processes of extracting scandium and REEs from various types of RM. At the same time, the options for reprocessing are very diverse. Since $\mathrm{Fe}, \mathrm{Al}, \mathrm{Ca}$ and $\mathrm{Ti}$ contain predominantly mineral phases, solutions of mineral acids such as $\mathrm{H}_{2} \mathrm{SO}_{4}[5,6], \mathrm{HCl}[6]$ and some organic acids [7, 8] are proposed as leaching reagents in hydrometallurgical processes. It is also proposed to use ionic liquids [9] and bioleaching processes [10] to extract REEs from RM.

As an alternative method of scandium extraction, the method of carbonate leaching [11, 12] was developed on the example of RM of aluminum refineries in Russia. One method of combined carbonate reprocessing is reductive melting of cast iron and self-scattering aluminium calcium slag, which is leached with aqueous solutions of sodium carbonate to obtain belite slimes [13].

Expediency of RM reprocessing technology in carbonate media, mainly in aqueous solutions of sodium carbonate or bicarbonate, is determined by reduced corrosion activity, increased safety for the environment, possibility of carbonate salts regeneration and solution circulation in the process cycle, as well as significant reduction of salt wastes.

The use of the carbonation method in the process of RM reprocessing leads to the neutralization of alkali and a decrease in the toxicity of $\mathrm{RM}$ (reduction of $\mathrm{pH}$ from 13-12 to less than 8.5-8). The neutralization products are $\mathrm{Na}_{2} \mathrm{CO}_{3}$ and $\mathrm{NaHCO}_{3}$ which serve as reactants for leaching REEs from RM, thereby returning to the process cycle. Use of carbon dioxide as a widely available and relatively inexpensive reagent, including in the composition of gases of sintering furnaces for carbonation, allows to reduce $\mathrm{CO}_{2}$ emission to some extent and reduce air pollution. Exclusion of concentrated mineral acids from technological processes allows to effectively integrate equipment of active alumina production for carbonate processing of RM, avoiding serious modification, as well as to use existing technological inrastructure [14]. The above aspects, as well as the possibility of REEs, $\mathrm{Zr}$, Ti and other valuable metals recovery from RM in the form of concentrates, make it possible to consider the carbonate leaching method as resource-saving and promising in the technology of RM reprocessing.

One of the most important tasks of improving carbonate-alkaline technology is to increase the extraction of scandium and other valuable components from RM and reduce their losses during further reprocessing. The solution of this complex technological task can be achieved only with the careful development of the chemical foundations of the carbonate leaching process, the identification of the main factors that increase the recovery of scandium and REEs, as well as the elimination of adverse factors that lead to the loss of target metals. Selection and optimization of conditions and modes of all applied processes of the considered carbonate-alkaline technology of RM reprocessing is important.

The main goal of this research was to develop and substantiate the concept of complex reprocessing of red mud using alkaline and carbonate media based on laboratory studies. 


\section{Materials and methods}

The raw material used for this research was represented by air-dried landfilled RM of the Bogoslovsky Aluminum Plant (SUAL Branch), which was obtained during reprocessing of bauxites from the Sredne-Timansky field (Komi Republic, Russia) by the combined Bayer sintering process. The chemical composition was determined by the ICP-MS method in the unit of $\mathrm{iCAP}^{\mathrm{TM}} \mathrm{Q}$ (Thermo Fisher Scientific, USA). The major elements in the original RM sample used are $\mathrm{Fe}, \mathrm{Al}, \mathrm{Si}, \mathrm{Ca}, \mathrm{Na}$, and Ti whose content (expressed in terms of oxides) is shown in Table 1. Residual water content in RM sample was not higher than 0.5 wt.\%.

Table 1. Major components composition in the original red mud sample.

\begin{tabular}{|c|c|c|c|c|c|c|}
\hline Compound & $\mathrm{Fe}_{2} \mathrm{O}_{3}$ & $\mathrm{Al}_{2} \mathrm{O}_{3}$ & $\mathrm{SiO}_{2}$ & $\mathrm{CaO}$ & $\mathrm{Na}_{2} \mathrm{O}$ & $\mathrm{TiO}_{2}$ \\
\hline wt., $\%$ & 42.1 & 12.7 & 9.4 & 7.8 & 4.8 & 4.3 \\
\hline
\end{tabular}

Red mud sample also contained trace elements, which include of Sc, Y, Ln, Zr, Nb, Hf, and Ga (see Table 2).

Table 2. Micro-components composition $\left(\mathrm{g} \mathrm{ton}^{-1}\right)$ in the original red mud sample.

\begin{tabular}{|c|c|c|c|c|c|c|c|c|c|c|}
\hline $\mathrm{Zr}$ & $\mathrm{Nb}$ & $\mathrm{Hf}$ & $\mathrm{Sc}$ & $\mathrm{Y}$ & $\mathrm{Ce}$ & $\mathrm{La}$ & $\mathrm{Pr}$ & $\mathrm{Nd}$ & $\mathrm{Sm}$ & $\mathrm{Gd}$ \\
\hline 1036.6 & 83.1 & 25.7 & 86.0 & 145.4 & 507.5 & 234.4 & 57.5 & 222.4 & 42.6 & 43.5 \\
\hline $\mathrm{Eu}$ & $\mathrm{Tb}$ & $\mathrm{Dy}$ & $\mathrm{Ho}$ & $\mathrm{Er}$ & $\mathrm{Tm}$ & $\mathrm{Yb}$ & $\mathrm{Lu}$ & $\mathrm{Ga}$ & $\mathrm{Th}$ & $\mathrm{U}$ \\
\hline 8.0 & 5.2 & 31.0 & 5.7 & 16.6 & 2.3 & 15.0 & 2.2 & 51.4 & 65.1 & 14.6 \\
\hline
\end{tabular}

Chemical pure grade $\mathrm{Na}_{2} \mathrm{CO}_{3}, \mathrm{NaHCO}_{3}, \mathrm{NaOH}$ and technical gas cylinder carbon dioxide were used.

Leaching of RM without ultrasonication (UT) was carried out in a 3-neck round-bottom glass flask with volume from $250 \mathrm{~mL}$ to $1000 \mathrm{~mL}$ placed in thermostat bath for maintaining a constant temperature of $50-85 \pm 0.1{ }^{\circ} \mathrm{C}$, with liquid-to-solid (L/S) ratio equal 5-10. Leaching time established on the basis of preliminary kinetic experiments was $120 \mathrm{~min}$, while the $\mathrm{CO}_{2}(\mathrm{~g})$ bubbling (carbonation) time for achieving and maintaining the constant value of $\mathrm{pH}=9.6-9.8 \pm 0.2$ was $20 \mathrm{~min}$. Volumetric flow rate of $\mathrm{CO}_{2}(\mathrm{~g})$ equal to $0.9 \mathrm{~L} \mathrm{~min}^{-1}$ was set by gas flowmeter (LZM-15Z visi-float).

Experiments with UT were performed with the usage of an ultrasonic horn waveguide (diameter of 50/30 mm) connected to an ultrasonic wave generator and to the control panel of the Bulava-P UZAP-3/22-OP unit (Ultrasonic Technologies Center, Russia). Ultrasonication was performed at the frequency of $22 \pm 1.65 \mathrm{kHz}$ and intensity of $10 \mathrm{~W} \mathrm{~cm}^{-2}$ ( $100 \%$ of unit power) in stationary mode. In all experiments, the depth of waveguide immersion in RM slurry was maintained at the fixed level of $5 \mathrm{~cm}$, since this parameter influences on the obtained results [15]. The cylindrical jacketed cell was closed with a cover to prevent water evaporation at prolonged UT. To prevent RM slurry overheating as a result of absorption of ultrasonic energy, a glass cell with water (as coolant) jacket was used. After loading of all reagents into reactor, supply of $\mathrm{CO}_{2}(\mathrm{~g})$ at flow rate $0.9 \mathrm{~L} \mathrm{~min}^{-1}$ was activated. At certain intervals, portions of RM slurry were withdrawn and filtered on a ceramic filter (Schott glass filter) at vacuum $(P=0.7-0.9$ bar) created by a water jet pump. 


\section{Results and discussion}

\subsection{Recovery of aluminium from red mud}

An complex approach to the reprocessing of RM dictates the need to recover aluminum from it as a useful product [16]. Two methods of aluminum recovery under conditions without autoclave treatment of RM have previously been discussed [17]. According to the first method, RM samples were directly leached by $\mathrm{NaOH}$ aqueous solutions at temperatures close to boiling points. According to the second method, the RM was presintered with $\mathrm{NaOH}$ or $\mathrm{Na}_{2} \mathrm{CO}_{3}$ and then leached by water. The maximum aluminum recovery was about $22 \%$ for the first method and about $30 \%$ for the second method.

The alkaline method of aluminum recovery contributes to the chemical enrichment of RM per iron. Depending on the conditions for the recovery of aluminum from the RM, the degree of enrichment of the RM by iron can range from 1.1 to 1.6. The best enrichment results in the range of 1.4-1.6 were achieved by sintering $\mathrm{RM}$ with $25 \% \mathrm{NaOH}$ at $550^{\circ} \mathrm{C}$ and leaching aluminum by both water and $4.0 \mathrm{M}$ solution of $\mathrm{NaOH}$, as well as by sintering with $15 \% \mathrm{Na}_{2} \mathrm{CO}_{3}$ at $900^{\circ} \mathrm{C}$ and two-step leaching of aluminum by $6.5 \mathrm{M}$ solution of $\mathrm{NaOH}$. For such conditions of the first stage of RM complex reprocessing, an increase in the Fe content in the final product up to $50 \%\left(\mathrm{Fe}_{2} \mathrm{O}_{3}\right.$ to $\left.\sim 80 \%\right)$ or more is already achieved. This allows the resulting iron-containing concentrate to be used commercially in iron smelting reduction processes.

The losses of scandium and REEs during alkaline leaching of aluminum do not exceed $0.1 \%$ and can be reduced with a decrease in the concentration of alkali in the initial leaching solution.

Aluminium is obtained from alkaline solutions by hydrolytic precipitation in the form of sodium hydroaluminocarbonate - $\mathrm{NaAlCO}_{3}(\mathrm{OH})_{2}$ (davsonite) in the presence of gaseous $\mathrm{CO}_{2}(\mathrm{~g})$. A study of the kinetics of this process showed that after $15 \mathrm{~min}$ of bubbling $\mathrm{CO}_{2}(\mathrm{~g})$ (flow rate $0.9 \mathrm{~L} \mathrm{~min}^{-1}$ ), aluminum completely passes into precipitation [18].

The carbonate solutions formed after precipitation of aluminum can be used in the subsequent step of carbonate leaching of scandium or regenerated into alkaline solutions by treatment with calcium hydroxide and precipitate calcium carbonate.

\subsection{Scandium and rare-earth elements recovery during carbonate leaching of red mud}

The solubility of sodium-containing scandium complexes in carbonate solutions reaches 5 $\mathrm{g} / \mathrm{l}$, and in hydrocarbonate - 10-12 g/1 [11], which theoretically allows to achieve the extraction of scandium from RM more than $99 \%$. However, in practice, scandium recovery does not exceed $15-25 \%$. The low recovery of scandium is due to the fact that only part of the scandium contained in the RM takes part in the carbonation reaction, the proportion of which usually does not exceed $30 \%$. The bulk of the scandium-containing phases are in the form of impurity inclusions in large mineral formations, which significantly complicates the isolation of scandium from RM. The low yield of scandium extraction in carbonate solutions reduces the overall efficiency of the process, which is reflected, first of all, in the economic component of the complex RM reprocessing technology.

One of the factors for intensification of the carbonate leaching of scandium from RM is carbonation using $\mathrm{CO}_{2}(\mathrm{~g})$. When RM slurry is carbonated by gaseous $\mathrm{CO}_{2}$, the $\mathrm{NaOH}$ contained in initial RM is neutralized and converted into $\mathrm{Na}_{2} \mathrm{CO}_{3}$ and/or $\mathrm{NaHCO}_{3}$. As a result of such a change in the medium, there is a significant increase in the solubility of $\mathrm{Sc}_{2} \mathrm{O}_{3}$ associated with the formation of stable complex scandium carbonate complexes $\mathrm{Na}_{(2 x-3)}\left[\mathrm{Sc}\left(\mathrm{CO}_{3}\right)_{x}\right]$, where $(x \geq 2)$. 
Under conditions of carbon dioxide treatment of RM, a number of solid phases (sodalite, calcium hydrogarnet, etc.) partially or completely decompose, which accumulate a certain amount of scandium and REEs. It also helps to improve the recovery of these important target components. When leaching $\mathrm{RM}$ with aqueous solutions $\mathrm{Na}_{2} \mathrm{CO}_{3}$ under carbonation conditions, Y, Ln, Ga, Ti, Zr, Hf and other valuable metals, which are also prone to the formation of soluble carbonate compounds, pass into the solution together with scandium.

Another option to increase the recovery of valuable components into the solution is to addition of complexing reagent to the solution, for example, a chloride ion in $\mathrm{NaCl}$. It is known that REE chloride compounds are highly soluble. The addition of chloride ions in the form of $\mathrm{NH}_{4} \mathrm{Cl}$ or $\mathrm{NaCl}$ can help dissolve the films of calcite $\left(\mathrm{CaCO}_{3}\right)$ and expose the surface of the particles of minerals, which facilitates the recovery of valuable components from RM during the subsequent use of the reagents. This makes it possible to increase the degree of their recovery into the solution. In the presence of $1.0 \mathrm{M} \mathrm{NaCl}$, the recovery of Sc is increased by $\sim 9, \mathrm{Ln}$ by $2-23 \%$, and $\mathrm{Zr}$ by $\sim 8$. The maximum recovery values of some REEs were $50-60 \%$

Promising methods for intensification of the carbonate leaching of REEs from RM include ultrasonic treatment, which allows reducing the process duration by $2-3$ times and increasing the recovery of REEs from RM. At the moment, the modes of the process of carbonation leaching of RM using ultrasonic treatment have been developed, allowing for 2-3 steps to achieve scandium recovery up to 55-59\%. In addition, the other methods for intensification the processes of Scandium and REEs recovery from RM, may include: vibration cavitation processing [19] and mechanical activation [20]. Combination of resinin-pulp with use of phosphorate ionite of grade KFP-12 or ampholite ANKF-80 with ultrasonic treatment of RM slurry during leaching by $\mathrm{NaHCO}_{3}$ solutions increases scandium recovery up to $51-54 \%$ [21].

\subsection{Concept of red mud complex reprocessing technology}

The scheme proposed in [22] for complex reprocessing of RM includes stages of recovery of aluminium and scandium from them, and recovery of iron-containing fraction by magnetic separation, with subsequent reduction of iron from it, and obtaining of nonmagnetic fraction of RM and its reprocessing by acid treatments. The need to enrich RM per iron by magnetic separation is due to the requirement for enriched products in which the iron content should not be less than $50 \%$, and which can be used by ferrous metallurgy in the production of steels and pig iron. It should be noted that the process of magnetic separation of the RM is quite complex and does not always lead to the desired effect, and the "non-magnetic" fractions obtained in this process contain a sufficiently large amount of iron. The acid treatment of such fractions will no doubt be accompanied by acid losses for iron dissolution, which will of course increase the cost of isolating other valuable components such as, for example, REEs. From this point of view, methods of chemical enrichment of RM per iron would be more effective.

The methods of recovery of aluminium, scandium and REEs from RM discussed in paragraphs 2.2 and 2.3 allow us to consider them as methods of chemical enrichment of RM per iron. In this case, depending on the degree of enrichment, the cakes after alkaline and carbonate leaching of valuable components can be directed to reductive melting to obtain two products: metallic iron and metallurgical slag containing all the remaining unrecovered components of the RM. These include underleached aluminum, scandium, zirconium, titanium and REEs non-recovered from RM at the first stages of reprocessing. The amount of slag obtained as a result of reductive melting of iron will not exceed $30-40 \%$ of the total amount of RM taken for reprocessing. In this case, the use of acidic 
hydrometallurgy methods to recover valuable components transferred to it from the slag will be more efficient and less expensive in terms of reagents cost. When using acid methods for reprocessing such slags, not only aluminum, scandium, zirconium, titanium residues can be more efficiently recovered from them, but also the entire sum of REEs that is not recovered in alkaline and carbonate media.

On the basis of the experimental data presented in this study and published earlier [17, 18], a concept of RM complex reprocessing technology was developed. This concept includes the following stages:

- pretreatment of RM before aluminum alkaline extraction. Options: (i) mechanical activation with solid $\mathrm{NaOH}$; (ii) sintering with $\mathrm{NaOH}$ or $\mathrm{Na}_{2} \mathrm{CO}_{3}$; (iii) wet milling in $\mathrm{NaOH}$ solutions;

- alkaline leaching of aluminum (without autoclave, in 2-3 steps, counterflow) by solutions of $\mathrm{NaOH} /$ water at increased temperature;

- $\quad$ solid-liquid separation by thickening, decantation or filtration;

- carbonation of alkaline aluminate solution;

- $\quad$ separation of dawsonite sludge from carbonate solution by decantation or filtration;

- drying of aluminum residue and obtainment of aluminum marketable compounds;

- carbonate leaching (2-3 counterflow steps) of rare-earth elements sum in conditions of cavitation-carbonation treatment at increased temperature;

- washing of solid residue after carbonate leaching;

- drying of iron-containing residue;

- $\quad$ separation of Sc and rare-earth elements from carbonate solution by precipitation and obtaining of rough concentrate;

- $\quad$ separation and obtainment of high-purity REEs oxides from rough concentrate;

- reduction melting of iron-containing residue with obtainment of pig-iron and metallurgical slag;

- mechanical separation of pig-iron and metallurgical slag;

- $\quad$ hydro-chemical reprocessing of metallurgical slag with release of $\mathrm{Al}, \mathrm{Sc}, \mathrm{Zr}$, Ti and REEs residues;

- regeneration of alkaline/carbonate solutions and recycling of alkaline reagents into technological cycle.

\section{Conclusions}

Laboratory-scale study of the aluminum alkaline leaching and carbonate leaching of scandium as well as analysis of the obtained results made it possible to develop the concept of a technological scheme for complex processing of RM to obtain intermediate products: (i) aluminum (sodium hydroaluminocarbonate), (ii) rough concentrate containing of Sc, $\mathrm{REE}, \mathrm{Ti}, \mathrm{Zr}$, which can be used to obtain individual high cost compounds, (iii) ironcontaining product suitable for use in ferrous metallurgy. The potential ability for reprocessing all red mud components into useful products, as well as the use of relatively low-aggressive media and the possibility of reagents regeneration, confirms the effectiveness of carbonate-alkaline processes in the red mud reprocessing technology. However, this method is tested only on samples of Russian Aluminum Plant red mud. Due to the difference in the mineralogical composition of red mud, this method may not be suitable for reprocessing other types of red mud. 


\section{Acknowledgements}

The research was supported by Mendeleev University of Chemical Technology. Project № T-2020-009. Measurements (studies) were made on the equipment of the Center for Collective Use of Mendeleev University of Chemical Technology.

\section{References}

1. V.L. Trushko, V.A. Utkov, V.Y. Bazhin, Journal of Mining Institute 227 (2017)

2. C.R. Borra, B. Blanpain, Y. Pontikes, K. Binnemans, T.V. Gerven, J. Sustain Metall. 2 (2016)

3. N. Zhang, L. Hongxu, L. Xiao-Ming, Rare Met. 35, 12 (2016)

4. W. Wang, Y. Pranolo, C.Y. Cheng, Hydromet. 108 (2011)

5. K. Hatzilyberis, T. Lymperopoulou, L.A. Tsakanika, K.M. Ochsenkühn, P. Georgiou, N. Defteraios, F. Tropelas, M. Ochsenkühn-Petropulu, Minerals 8, 3 (2018)

6. R.M. Rivera, B. Ulenaers, G. Ounoughene, K. Binnemans, T.V. Gerven, Min. Eng. 119 (2018)

7. C.R. Borra, Y. Pontikes, K. Binnemans, T.V. Gerven, Min. Eng. 76 (2015)

8. E. Ujaczki, Y. Zimmermann, V. Feigl, M. Lenz, Proceedings of Bauxite Residue Valorisation and Best Practices Conference, Leuven, Belgium, 5-7 October, 2015

9. P. Davris, E. Balomenos, D. Panias, I. Paspliaris, Rare earths industry (Elsevier, Amsterdam. 2016)

10. Y. Qu, H. Li, W. Tian, et al, Miner Eng. 81, 1-4 (2015)

11. N.A. Sabirzyanov, S.P. Yatsenko, Hydrochemical methods of complex processing of bauxite (URO RAS, Yekaterinburg, Russia. 2006)

12. S.P. Yatsenko, N.A. Sabirzyanov, L.A. Pasechnik, G.M. Rubinstein, V.N. Diev, L.M. Scriabneva, Patent RU2247788 (2005)

13. V.A. Derevyankin, M.I. Gasik, L.I. Anelok, Non-ferr. Met. 5 (1981)

14. I.N. Pyagay, Doctoral (Tech.) Dissertation (Mining University, St. Petersburg, 2017)

15. H. Mayer, A. Mentler, M. Papakyriacou, N. Rampazzo, Y. Marxer, W.E.H. Blum, International Agrophysics 16, 1 (2002)

16. I.N. Pyagay, V.L. Kozhevnikov, L.A. Pasechnik, V.M. Skachkov, Journal of Mining Institute. 218 (2016)

17. A.V. Boyarintsev, M.M. Aung, H.Y. Aung, S.I. Stepanov, Vestnik VGUIT 80, 3 (2018)

18. S.I. Stepanov, M.M. Aung, H.Y. Aung, A.V. Boyarintsev, Vestnik VGUIT 80, 4 (2018)

19. G.N. Klimentenok, V.S. Anashkin, S.E. Vishnyakov, A.V. Panov, Patent RU2536714 (2014)

20. V. Rychkov, M. Botalov, E. Kirillov, S. Kirillov, V. Semenishchev, G. Bunkov, D. Smyshlyaev, Hydromet 199 (2021)

21. I.R. Boboev, P.V. Alexandrov, V.A. Imidiev, Patent RU2630183 (2017)

22. S.I. Stepanov, M.M. Aung, A.V. Boyarintsev, A.V. Goziyan, A.M. Chekmarev, Actual issues of obtaining and applying REM and RM-2017 (Moscow, Russia, 2017) 